\title{
An Analysis of Evaluating College English Teaching Materials*
}

\author{
Yu Meng \\ School of Languages and Literature \\ Harbin Institute of Technology, Weihai \\ Weihai, P.R. China
}

\author{
Guangxiao Shi \\ School of Languages and Literature \\ Harbin Institute of Technology, Weihai \\ Weihai, P.R. China
}

\author{
Yuan $\mathrm{Yu}$ \\ School of Languages and Literature \\ Harbin Institute of Technology, Weihai \\ Weihai, P.R. China
}

\begin{abstract}
Evaluating teaching materials is of great importance in college English teaching. It is an indispensible process which makes both teachers and students understand the materials better and helps their teaching and learning. This paper aims at analyzing the systematic criteria of evaluating college English teaching materials and the factors which would affect the process of evaluating.
\end{abstract}

Keywords—evaluating; college English; teaching materials

\section{INTRODUCTION}

Evaluating teaching materials effectively in college English teaching plays quite an important role. It is a very crucial professional activity for college English teachers, for teachers use textbooks during their teaching process. Their teaching should be based on sound theoretical and practical considerations. Apart from that, evaluating teaching materials can both facilitate the selection of new materials and reconsider old ones on a regular basis. In many situations, teachers are users of other people's ideas because they neither have the time nor resources to produce their own materials and most often they are given a textbook to teach from. As a result, choosing the right textbook is becoming more and more important at all levels in schools. It is, therefore, important for teachers to develop an awareness as well as ability to evaluate textbooks available to them. Only through the process of evaluating textbooks, can teachers maximize the strength of materials and supplement them according to the needs of their own students [1]. With the efforts of all sides, textbook evaluation and selection have evolved from simple procedure to systematic actions.

Teaching materials contain materials teachers teach and students learn. In a broad sense, they include materials outside the classroom such as exercise books, tapes, videos,

* This article is sponsored by Teaching and Research Program (YYWX201703) of School of Languages and Literature of Harbin Institute of Technology, Weihai, and China Foreign Language Education Fund (ZGWYJYJJ201B81) newspapers, magazines, radio and television programs and the like. In a narrow sense, they refer to textbooks specifically which are core teaching materials and a concrete manifestation of the syllabus. Textbooks include a stage of the learning content, such as language knowledge and language skills. Moreover, the application of modern computer technology such as multimedia software and website information as students' learning sources, can offer structured active learning for students and to extend learning beyond the classroom and construct a flexible, personalized, and interactive learning environment. Though teaching materials cover larger and larger scope today, the term "textbooks" is still widely used simply because for some people its reference has expanded from books to all the materials used around a particular textbook and for others and it still refers to a textbook independent of the other materials.

\section{Aims OF Evaluating TEACHING MATERIALS}

There are three main purposes for textbook evaluation: selecting a new text book; testing effectiveness of a textbook; designing a textbook [2]. We select textbooks after we evaluate them. When we evaluate a textbook with an intention of adoption, we try to match what is offered by the book with the needs of our learners and our teaching context. Despite the great efforts that textbook writers make to meet the needs of the intended users, textbooks are subject to adaptation when they are actually used in the classroom. Thus, a careful evaluation before usage is of significance. It will offer help in checking whether the textbooks in series maintaining the inner link between these books by avoiding sudden jerk and inverted repeat; whether the textbooks embody the new idea of the new syllabus and pay more attention to the basic skills; whether the textbooks reflect the special requirements of the target learner by introducing the new ideas, methods and technique abroad; whether the set of books tries to take fully inclusive and equitable measures and give consideration to both language and culture; finally, as course book selection is a vital matter 
involving state talents training, whether details of the compilation of the books are all exact and precise.

\section{Previous Studies Home AND ABroAD}

Teaching materials evaluation can be traced back to 1970 s in Western education field. It takes off in 1990s and influences many other countries' evaluating theory, including China. There are some significant theorists whose views laid the foundation of evaluating theory. Gardner \& Lambert (1972) focused on motivation, proposing an integrative-instrumental duality, which became widely accepted and confirmed by a number of studies. They found that success in language attainment was dependent on learners' affective reactions toward the target linguistic-cultural group and gave validity to the study of motivation in second language acquisition [3].

In 1980s, textbook evaluation caused the concern of many scholars at home and abroad. O'Neill (1982) pointed out that most teachers are inclined to follow the text's methodology, vocabulary and sequence to the letter [4]. Ariew (1982) also regarded the textbook as a means of motivating students to pursue language for their purposes. Therefore, it is important for teachers to know how to choose the best material for instruction, how to make supplementary materials for the class, and how to adapt materials [5]. Cunningworth (1989) made numerous materials in the evaluation of important principles: "critical materials related with the teaching objectives: To clear the purpose of language learning, and to select those that can help students effectively use the language of teaching materials; consider the language learning process and learners interrelationship." He pointed out that the materials should be consistent with the students' need for learning objectives; materials should reflect the students' present and future language needs, to help students effectively use the language; materials should take into account the needs of students as learners, facilitate their learning process, not to arbitrarily impose their so-called "method"; materials should clearly support the role of learning to promote students' language learning. Cunningworth's attention to students' needs and the learning process for materials research adds a new perspective. Deci and Ryan (1985) extend the intrinsic/extrinsic theory with a more detailed construct following the main principles of what they called self-determination theory. They claim that learners who are interested in learning tasks and outcomes for their own sake rather than for rewards are likely to become more effective learners [7]. The year 1987 saw a collection of essays published by Sheldon on materials evaluation. He wrote papers to explore the theoretical and practical evaluation of materials issues for further in-depth study provides important elements [6]. Dornyei (1994) put forward three sets of motivational components were identified by: a) course-specific motivational components; b) teacher-specific motivational components; c) group-specific motivational components. This framework appears to be particularly useful in describing course-specific motives [8].

Influenced by Western evaluating theory, some of our Chinese experts and scholars have begun to attach importance to foreign materials evaluation criteria. Wang Qiang, He Anping, Xi Jimei and Cheng Xiaotang, these professors make great contribution to China's teaching material evaluation theory.

The above mentioned experts and scholars both abroad and home have made great contributions in the progress of evaluating teaching materials in reality practice and guided the direction in college English teaching.

\section{CRITERIA OF EVALUATING COLLEGE ENGLISH TEXTBOOKS}

\section{A. On External Evaluation}

The systematic evaluation of a textbook should be a longitudinal one. The first step may focus on its external evaluation, namely, macro evaluation. According to McDonough and Shaw (2003), external evaluation involves, looking at the claims made by the authors [9]. It can be found in the introduction to the student's book like their ideas, beliefs and thinking pattern about language learning. What we really need to know is what views of language learning they are based on[10].Other factors to take into consideration include how the language has been presented and organized into teachable lessons. It is necessary to look through the contents to see whether they reflect the author's attitudes. A closer look at the contents table reveals the following secondary organizing principles: function and grammar.

The external evaluation can be carried on as follows: first, check the syllabus to see whether the syllabus matches the table of content. If the textbook contains activities involving mixes skills, structures, lexis, notions, functions and tasks demanded by the syllabus, then it can be held that the textbook fits in its counter syllabus. Second, check the grading and sequencing. Third, check publisher's and authors' claim. Fourth, check the layout of the textbook. At last, check the additional materials with the textbook, like CD-ROM, students' workbook and instructor's manual.

\section{B. On Internal Evaluation}

Apart from external evaluation, internal evaluation is also demanded, which intends to investigate the following aspects of a textbook: Does it include the presentation and practice of all the skills? Are the grading and sequencing of the materials natural and appropriate? In the language input selected reflect the interest or age level of the intended learners? Are there enough skills and strategy practice? Are the writing tasks realistic and motivating for the age group? Do the speaking activities represent as much as possible real interactions? Are there adequate and various reading discourse? (including sketches, plays, a cultural text, letters and literature articles) Can the reading comprehension exercises encourage both reading for gist and reading for detail? Does it contain grammar and lexis illustration in detail? Can it encourage the teacher and the learner to play their role fully?

On the basis of both external evaluation and internal evaluation, it becomes much easier to make decision in terms of the suitability of the textbook. The list of general features of "good" textbooks according to Tomlinson (1998) is quite useful: Textbooks should help students feel at ease, develop their confidence, provide students with opportunities to use the 
target language to achieve communicative purposes and expose students to language in authentic use. Good textbooks should attract the students' curiosity, interest and attention. Textbooks should take into account the positive effects of language teaching, students' differences in learning styles, and students' differences in affective factor. At last, good textbooks should maximize learning potential by encouraging intellectual, aesthetic and emotional involvement which stimulates both right and left brain activities [11].

\section{FACTORS AfFecting Evaluating Process}

It is apparently that the process of evaluating college English teaching materials cannot be carried in vacuum. There is many a factor that can affect this process. In the first place, teachers' authority of selecting textbooks matters a lot. Most often, teachers are offered a / a series of specific textbook(s) to use in their teaching. However, teachers are the one who can learn about their students' needs and demands at the earliest moment. Thus it is quite necessary to let teachers get involved in selecting textbooks instead of being given or offered textbooks by others. Secondly, the teachers' teaching concepts do matter. The teachers' teaching concepts refer to the teachers' systematic and essential understanding of teaching activity. It should be student-oriented to learn about students' interests, English language ability and their study aims and goals, and then to carry out the unified teaching syllabus and use textbooks flexibly. Thirdly, students' demands and requirements do matter in textbook selecting and evaluating. The students are also the users of textbooks. Their demands should be taken into consideration in this process; otherwise, the evaluation is not an objective and all-rounded on. Fourthly, the criteria of evaluating will affect the evaluating process. To be specifically, a series of practical, objective, well-designed and full-covered criteria can make the process go through more smoothly and effectively. Last but not least, the support of software and hardware conditions from the school. Some textbooks require special equipment in application to make it in full use. If there would be this kind of equipment support, the textbook will, no doubt, be better employed. Considering these factors carefully, the selecting and evaluating of textbooks could be made improved.

\section{CONCLUSION}

As a unique subject, college English teaching should focus on students' language knowledge; equally important is training students' practical English skills. Among classroom related factors learning material certainly plays an essential part. The present evaluation generalized some implications for the selection, adaptation and development of teaching materials for College English teaching and learning. Although the textbook authors attempt to make their materials meet the needs of all learners, none of them can make it. Hence it is teachers' duty to use the material flexibly, as a resource of the course. In order to choose a set of appropriate materials for a particular group of students, it is important to explore students' interest as well as need. Supplementary material is indispensable and necessary. What's more, using the textbook in different way should also be considered. Meanwhile, in Chinese education context teaching should stick with the requirements of syllabus as well.
Teachers should be given authority to evaluate, select and adapt textbooks, have initiative and know how to evaluate, select and adapt textbooks. With the implementation of the new curriculum in the new era and with the policy of decentralization in producing and publishing textbooks, a variety of textbooks are available and many teachers are being involved in selecting and adapting textbooks for their schools. In the process of curriculum reform teachers are encouraged to give their own advice on the usage of textbooks. This is not only the power of teachers, but also implying a responsibility of teachers to meet the needs of their teaching and their students.

\section{REFERENCES}

[1] Hedge, T. Teaching and Learning in the Language Classroom. Oxford:Oxford University Press, 2000

[2] Xia Jimei. Modern foreign language course design theory language practice. Shanghai: Shanghai Foreign Language Education Press, 2002.

[3] Gardner R C, Lambert W. Attitudes and Motivation in Second Language Learning.Rowley, MA:Newbury House, 1972.

[4] Neill O R. Why use text books? ELT Journal, 1982,36(2).

[5] Ariew R. The textbook as a curriculum. Higgs T V,Curriculum, Competence, and the Foreign Language Teacher. The ACTFL Foreign Language Education Series. Skokie: National Textbook Co.1982.

[6] Cunningworth, A.1989. Evaluation and Selecting EFL Teaching Materials.London: Heinemann, 3.Hutchinson, T. \&amp; Waters. A.1987. English for Specific Purpose.Cambridge: Cambridge University Press.

[7] Deci E L,Ryan R M. Intrinsic motivation and self-determination in human behavior. New York:Plenum Press, 1985.

[8] Dornyei Z. Motivation and motivating in the foreign language classroom.Modern Language Journal,1984(78).

[9] McDonough, J. \&amp; C.Shaw. Materials and Methods in ELT.Cambridge and Mass: Blackwell, 2003.

[10] Hutchinson, T. What's underneath?: An interactive view of materials evaluation. In Sheldon, L. E. (eds.), Sociolinguistics. Harmondsworth: Penguin, 1987.

[11] Tomlinson, B. Introduction. In Tomlinson, B. (ed.) Materials Development in Language Teaching. Cambridge: Cambridge University Press, 1998. 